\title{
Rottlerin as a novel chemotherapy agent for adrenocortical carcinoma
}

\author{
Yi Zhu ${ }^{1,2}$, Minjie Wang $^{3}$, Xu Zhao ${ }^{2,4}$, Lei Zhang ${ }^{2}$, Yigao Wu², Bangqi Wang ${ }^{2}$, \\ Weilie $\mathrm{Hu}^{2}$ \\ ${ }^{1}$ Third Military Medical University, Chongqing, P.R. China \\ ${ }^{2}$ Guangzhou General Hospital of Guangzhou Military Command, Guangzhou, Guangdong, P.R. China \\ ${ }^{3}$ No. 422 Hospital of PLA, Zhanjiang, Guangdong, P.R. China \\ ${ }^{4}$ Southern Medical University, Guangzhou, Guangdong, P.R. China
}

Correspondence to: Weilie Hu, email: huwl-mr@vip.sina.com

Keywords: adrenocortical carcinoma, rottlerin, Wnt/ $\beta$-catenin, anticancer agent

Received: October 07, $2016 \quad$ Accepted: January 24, $2017 \quad$ Published: February 09, 2017

\section{ABSTRACT}

Adrenocortical carcinoma (ACC) is a rare, but aggressive endocrine malignancy with a generally poor clinical outcome. There is no effective therapy for advanced and metastatic ACC. In our study, we found that an existing drug (rottlerin) exerted its tumour-suppressive function in ACC. Specifically, rottlerin inhibited cellular proliferation of ACC cell lines (NCI-H295R and SW-13) in a dose- and time-dependent manner. We also found that rottlerin induced cell apoptosis and promoted G0/G1 cell cycle arrest in ACC cell lines. The cellular migration and invasion of ACC cell lines were decreased after treatment with rottlerin. Further, the molecular expression of lipoprotein receptor related protein 6 (LRP6) and $\beta$-catenin were down-regulated in rottlerin-treated ACC cells, which indicated that Wnt/ $\beta$-catenin signaling was involved in the tumour-suppressive function of rottlerin. To further confirm the anti-tumour function of rottlerin, a nude mouse ACC xenograft model was used. The xenograft growth curves and TUNEL assays demonstrated that rottlerin inhibited proliferation and induced apoptosis in the ACC xenograft model. Furthermore, we verified that rottlerin down-regulated the expression of LRP6 and $\beta$-catenin in vivo. The ACC cell line and xenograft mouse model data indicated that rottlerin significantly inhibited proliferation and induced apoptosis of ACC cells, likely via suppression of the Wnt/ $\beta$ catenin signaling pathway. Our study indicated the potential therapeutic utility of rottlerin as a novel and potential chemotherapeutic agent for ACC.

\section{INTRODUCTION}

Adrenocortical carcinoma (ACC) is a rare, but typically aggressive malignancy with an estimated annual incidence of $0.7-2.0$ cases per million population. ACCs are highly aggressive with a poor prognosis and an overall survival rate at 5 years of only $25 \%-50 \%$ in most series [1, 2]. Until recently, radical surgical resection has been the only potentially curative option for ACC; however, approximately $40 \%$ of patients initially present with distant metastases. Even after seemingly complete removal of the tumor, recurrences occur in approximately $60 \%-80 \%$ of ACC patients [3]. Unfortunately, there is no effective therapy for patients with advanced or recurrent
ACC. The combination of a cytotoxic drug and mitotane is recommended as first-line therapy in advanced ACCs, but the poor therapeutic efficiency $(<40 \%)$ and severe side effects limits clinical utility [4]. Therefore, new agents for ACC treatment are urgently required.

Rottlerin(1-[6-[(3-acetyl-2,4,6-trihydroxy-5methylphenyl)methyl]-5,7-dihydroxy-2,2dimethyl-2H1-benzopyran-8yl]3-phenyl-2-Propen-1-one), also known as mallotoxin, is a natural plant polyphenol.Rottlerin is a traditional Indian medicine previously used as an antagonist of fertilization and treatment for cestode and trematode infections [5]. In recent years, rottlerin has been shown to regulate several cell processes, including cell circle regulation, cellular proliferation, apoptosis, 
autophagy, and migration [6]. Numerous studies have demonstrated that rottlerin plays an important role in antitumor activity in several cancers like prostate cancers and pancreatic cancer,and has great potential as a novel chemotherapeutic agent. Other studies have shown that rottlerin suppresses tumor cell survival in breast cancer, likely via suppression of the $\mathrm{Wnt} / \beta$-catenin signal pathway [7]. Within the adrenal cortex, the Wnt/ $\beta$-catenin cascade is involved in adrenal development and differentiation [8]. Indeed, abnormal functioning of the $\mathrm{Wnt} / \beta$-catenin signal pathway may lead to adrenal tumourigenesis $[9,10]$. In patients with ACC, $\beta$-catenin activation is associated with decreased overall survival. The $\mathrm{Wnt} / \beta$-catenin pathway is expected to be an efficient targeting strategy for the treatment of ACC [11, 12]. Therefore, we sought to investigate the potential role and preliminary mechanisms of rottlerin in tumor cell proliferation, migration, and invasion in ACC cell lines and an ACC xenograft mouse model. In addition, we explored the potential therapeutic utility of rottlerin as a novel and potential chemotherapeutic agent for ACC.

\section{RESULTS}

\section{Rottlerin inhibits $\mathrm{ACC}$ cell proliferation in vitro}

To investigate the effects of rottlerin on ACC, we first evaluated whether or not rottlerin decreases viability in ACC cell lines. NCI-H295R and SW-13 cells were treated with rottlerin at the indicated concentration for 24 , $48,72,96$, and $120 \mathrm{~h}$. It was shown that rottlerin inhibited proliferation of ACC cells in a time- and dose-dependent manner (Figure 1A). At a concentration of $4 \mu \mathrm{M}$, rottlerin inhibited approximately $44.0 \%$ and $43.2 \%$ of NCI-H295R and SW-13 cells, respectively, after treatment for $48 \mathrm{~h}$. In contrast, when exposed to $8 \mu \mathrm{M}$ rottlerin for $72 \mathrm{~h}$, the inhibition ratio (1-viable cell\%) was up to $70 \%$ in $\mathrm{SW}$ 13 cells and $80 \%$ in NCI-H295R cells. The 5-day growth curves showed that the growth of rottlerin-treated cells was relatively slower than cells not treated with rottlerin in a dose-dependent manner (Figure 1B). The 48-h IC50 was $5.02 \mu \mathrm{M}$ in NCI-H295R cells and $4.87 \mu \mathrm{M}$ in SW-13 cells.

\section{Rottlerin induced ACC cell apoptosis in vitro}

To further elucidate the mechanism by which rottlerin inhibits cellular growth in ACC cells, we determined whether or not rottlerin induces apoptosis in ACC cells. Flow cytometry was performed to show the apoptosis rate of ACC cells after treatment with rottlerin at the indicated concentration $(5 \mu \mathrm{M}$ [approximately the $48 \mathrm{~h}$ IC50] and $2.5 \mu \mathrm{M}$ [approximately half of the $48 \mathrm{~h}$ IC50]). The percentage of apoptosis (early apoptosis plus late apoptosis) was identified in NCI-H295R and SW13 cells after rottlerin treatment (Figure 2A). The results showed an increase in the percentage of apoptotic cells in the rottlerin-treated group compared with the control and DMSO groups. After treatment with $2.5 \mu \mathrm{M}$ rottlerin for $48 \mathrm{~h}$, the percentage of apoptotic cells reached $13.0 \%$ in the NCI-H295R cells and $10.9 \%$ in the SW-13 cells. After treatment with $5 \mu \mathrm{M}$ rottlerin for $48 \mathrm{~h}$, the percentage of apoptotic cells reached $43.3 \%$ in the NCI-H295R cells and $38.3 \%$ in the SW-13 cells. The results suggest that rottlerin induces apoptosis in a dose-dependent manner. The results of $\mathrm{AO} / \mathrm{EB}$ staining support these conclusions regarding morphology changes. The apoptosis rate increased in the rottlerin-treated group compared with the control and DMSO groups with $\mathrm{AO} / \mathrm{EB}$ staining (Figure 2B, $* p<0.05)$. The apoptosis rate in the $5 \mu \mathrm{M}$ rottlerin-treated group was higher compared to the $2.5 \mu \mathrm{M}$ rottlerin-treated group (Figure $2 \mathrm{~B}, * p<0.05$ ).

\section{Rottlerin caused cell cycle arrest of ACC cells in vitro}

Rottlerin inhibited cellular proliferation and may also be involved with cell cycle arrest. Therefore, we investigated the effect of rottlerin on the cell cycle of ACC cells using flow cytometry analyses. After treatment with $5 \mu \mathrm{M}$ rottlerin for $48 \mathrm{~h}, \mathrm{G} 0 / \mathrm{G} 1$ cell cycle arrest occurred in ACC cells (Figure 1C). The percentage of cells in the G1 phase was $85.14 \%$ in NCI-H295R cells and $81.88 \%$ in SW-13 cells, which was significantly increased compared with the control group (Figure 1D, ${ }^{*} p<0.05$ ).

\section{Rottlerin inhibited cell invasion and migration of ACC cells}

Invasion and migration are related to the malignant features of ACCs [13]. To determine if rottlerin inhibits cell invasion and migration of ACC cells, we performed transwell invasion and migration assays. In the rottlerin treatment group, the invasion of ACC cells was impaired by rottlerin $(5 \mu \mathrm{M})$; significantly fewer cells migrated to the lower side of the transwell chamber membrane than the control group (Figure $2 \mathrm{C},{ }^{*} p<0.05$ ).

The results of wound healing assay demonstrated that the migration rate of SW-13 cells was significantly reduced by rottlerin $(5 \mu \mathrm{M})$ compared with the control group (Figure $3 \mathrm{~A})$. The $24 \mathrm{~h}$ migration rate was significantly decreased in SW-13 cells (Figure $3 \mathrm{C},{ }^{*} p<0.05$ ).

\section{Rottlerin inhibited tumor growth in vivo}

To investigate the effect of rottlerin on anti-tumor activities in vivo, we established a SW-13 xenograft tumor model in nude mice. With the administration of rottlerin for 4 weeks, tumor sizes and body weight were measured every 4 days. Assessment of tumor volume showed that the rottlerin-treated groups had delayed tumor growth compared to the control group and the group treated with DSMO (Figure 4A). There was no significant weight differences 
among the groups and there was no toxicity or side effects in the mice after 4 weeks of treatment (Figure 4B). Then, mice were sacrificed and the xenografts were extirpated. As shown in Figure 5, tumors were smaller in the experimental groups than the control and DSMO groups, and tumors were smaller in the rottlerin $4 \mathrm{mg} / \mathrm{kg}$ group than the rottlerin $2 \mathrm{mg} / \mathrm{kg}$ group. The mean volume of the tumors decreased from $3.23 \mathrm{~cm}^{3}$ (control) and $3.35 \mathrm{~cm}^{3}$ (DMSO) to $1.56 \mathrm{~cm}^{3}$ (rottlerin $4 \mathrm{mg} / \mathrm{kg}$ ) and $1.94 \mathrm{~cm}^{3}$ (rottlerin $2 \mathrm{mg} / \mathrm{kg}$ ); the difference was statistically significant $(p<0.05)$. TUNEL assays were performed to assess the anti-tumor activity of rottlerin in vivo (Figure 4C). The TUNEL assays indicated that the rottlerin-treated groups had higher apoptotic rates compared with the control and DMSO-treated groups.

\section{Rottlerin suppressed the Wnt/ß-catenin signaling pathway}

To determine if rottlerin suppresses the $\mathrm{Wnt} / \beta$ catenin signaling pathway in ACC, and to elucidate the mechanism by which rottlerin mediates ACC cell apoptosis, some signaling molecules in the Wnt/ $\beta$-catenin pathway were examined. Based on result of Western blotting, We can conclude that rottlerin reduced the expression of $\beta$-catenin, LRP6, and p-LRP in ACC cells in a dose-dependent manner (Figure 3B).

Furthermore, we performed H\&E (Figure 4D) and immunohistochemistry staining in xenograft tissues, and the results showed that rottlerin also down-regulated the expression of $\beta$-catenin, LRP6, and p-LRP compared with the control and DMSO-treated groups in vivo (Figure 5, $\left.{ }^{*} p<0.05\right)$. Moreover, in the higher dose-treated group (rottlerin $4 \mathrm{mg} / \mathrm{kg}$ ), the expression of $\beta$-catenin, LRP6, and p-LRP was lower than the lower dose-treated group (rottlerin $2 \mathrm{mg} / \mathrm{kg}$ ).

\section{DISCUSSION}

There is no effective treatment for patients with locally advanced and metastatic ACC. Development of effective treatment or novel agents for patients with locally advanced and metastatic ACC is significant [14]. Rottlerin, which is extracted from Mallotus philippinensis, is a polyphenol that has been used as an ant-helminthic or a fertilization antagonist. Rottlerin has been used in humans for many years, has a good safety profile, and exhibits little toxicity, even after long-term exposure [5]. Recently, rottlerin has been shown to exhibit anti-neoplastic activity in several cancers, including breast, prostate, colorectal, and pancreatic cancers $[7,15,16]$ by inhibiting various cellular pathways known to play important roles in carcinogenesis, like $\mathrm{Wnt} / \beta$-catenin signaling pathway and mammalian target of rapamycin complex 1 (mTORC1) signaling.however, its antineoplastic activity in ACC has rarely been studied.

Wnt/ $\beta$-catenin signaling plays an important role in embryonic development and can lead to tumor formation when aberrantly activated [14, 17]. The Wnt pathway has been examined in relation to many cancers, such as leukemia, melanoma, lung cancer, and colorectal cancer
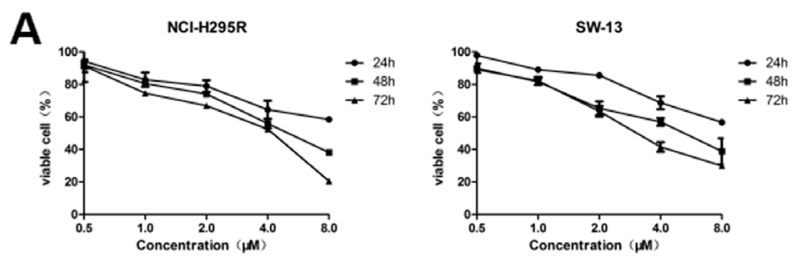

B
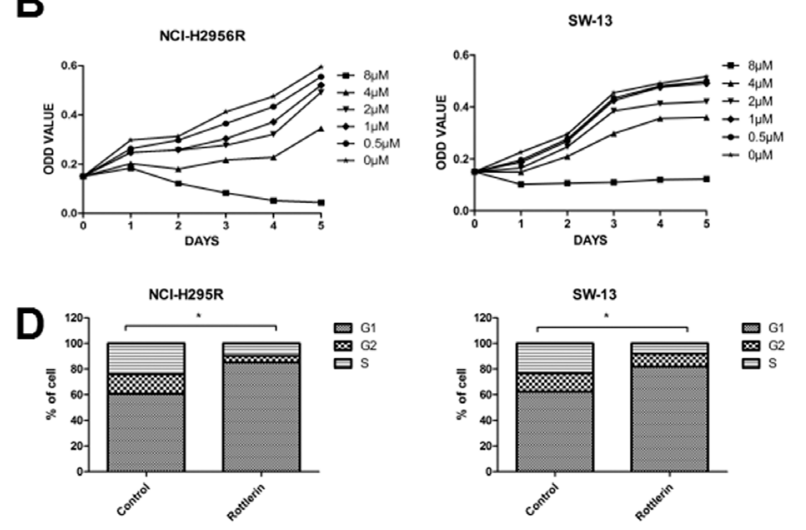
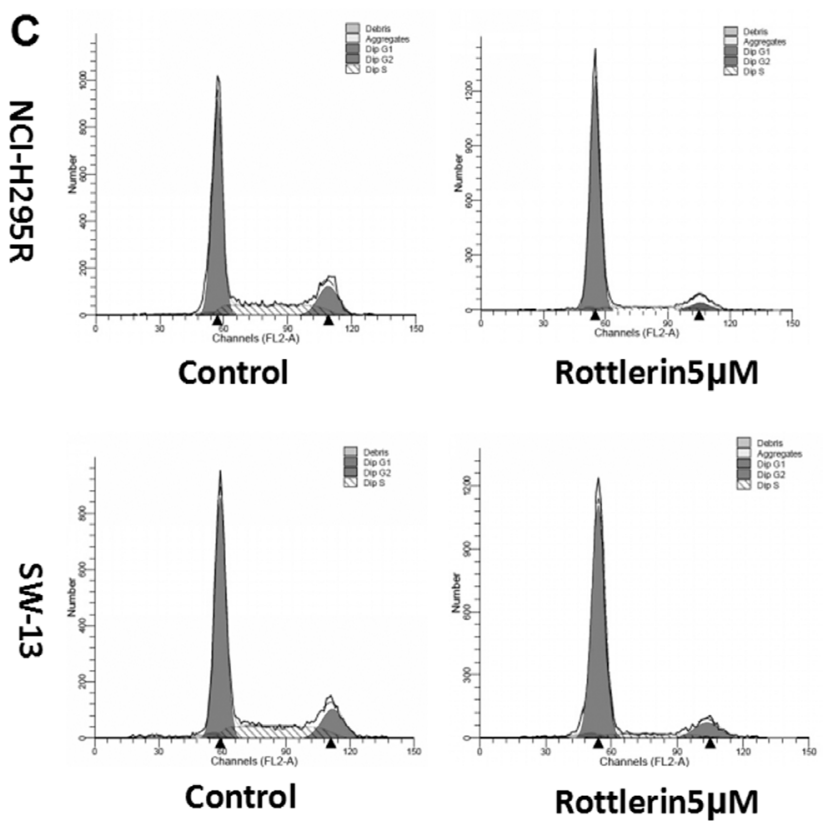

Figure 1: (A) Rottlerin both inhibited proliferation of ACC cells in a dose- and time-dependent manner. (B) Growth curve of NCI-H295R and SW-13 cells treated with rottlerin $(0,0.5,1,2,4$, and $8 \mu \mathrm{M})$ for 5 days. The growth of rottlerin-treated cells was relatively slower than untreated cells in a dose-dependent manner. (C) Rottlerin caused cell cycle arrest of ACC cells at the G0/G1 phase after treatment with $5 \mu \mathrm{M}$ rottlerin for $48 \mathrm{~h}$ based on flow cytometric analysis. (D) Rottlerin caused cell cycle arrest of ACC cells at the G0/G1 phase compared with control $(* p<0.05)$. 
[18]. Activation of the Wnt/ $\beta$-catenin pathway occurs in ACC and is frequently caused by activating mutations of the gene encoding Wnt/ $\beta$-catenin [18]. Therefore, blocking the $\mathrm{Wnt} / \beta$-catenin pathway is expected to be an efficient targeting strategy for the treatment of ACCs [4]. Recent studies have reported that rottlerin blocks the Wnt $\beta$ catenin signaling pathway in some cancers, including colorectal, prostate, and breast cancers [7].

In this study, we examined the effect of rottlerin on ACC cells. The results showed that rottlerin inhibited proliferation, induced apoptosis and G0/G1 cell cycle arrest, and decreased invasion and mobility of ACC cell lines. Furthermore, the results of animal experiments showed that rottlerin inhibited tumor growth in vivo, and there was no obvious toxic effect in nude mice. The results showed that rottlerin has anti-neoplastic activity in ACC, and could serve as a novel agent for the treatment of ACC.

We then turned to study the mechanism underlying the antineoplastic activity of rotterlin against ACC. We detected the expression of several key components of the Wnt/ $\beta$-catenin signaling pathway in ACC cell lines and xenografts of nude mice treated with rottlerin. Based on Western blot and immunohistochemistry staining, the expression of $\beta$-catenin, LRP6, and p-LRP6 was downregulated after treatment with rottlerin. We deduced that rottlerin plays a role as an anti-tumor agent in ACC related to $\mathrm{Wnt} / \beta$-catenin signaling pathway,likely via suppression of the $\mathrm{Wnt} / \beta$-catenin signaling pathway.

$\beta$-catenin, which is encoded by the CTNNB1 gene, is a key component of this signaling pathway and has multiple functions, including mediation of cell adhesion and signal transduction $[19,20]$. $\beta$-catenin combines with a variety of proteins to regulate cell proliferation and differentiation, which is critical for embryonic development and tumorigenesis [21]. In ACC, accumulation of $\beta$-catenin has frequently been noted, indicating activation of the Wnt signaling pathway. Mutations in $\beta$-catenin have been associated with a poor prognosis in patients with ACC, and higher-grade ACC is associated with higher $\beta$-catenin expression [22]. In our study, $\beta$-catenin was down-regulated by rottlerin in ACC cells, both in vitro and in vivo.

LRP6, an indispensable co-receptor for the Wnt signaling pathway, is a member of the low-density lipoprotein receptor family, which interacts with the seven transmembrane receptor of the Frizzled $(\mathrm{Fzd})$
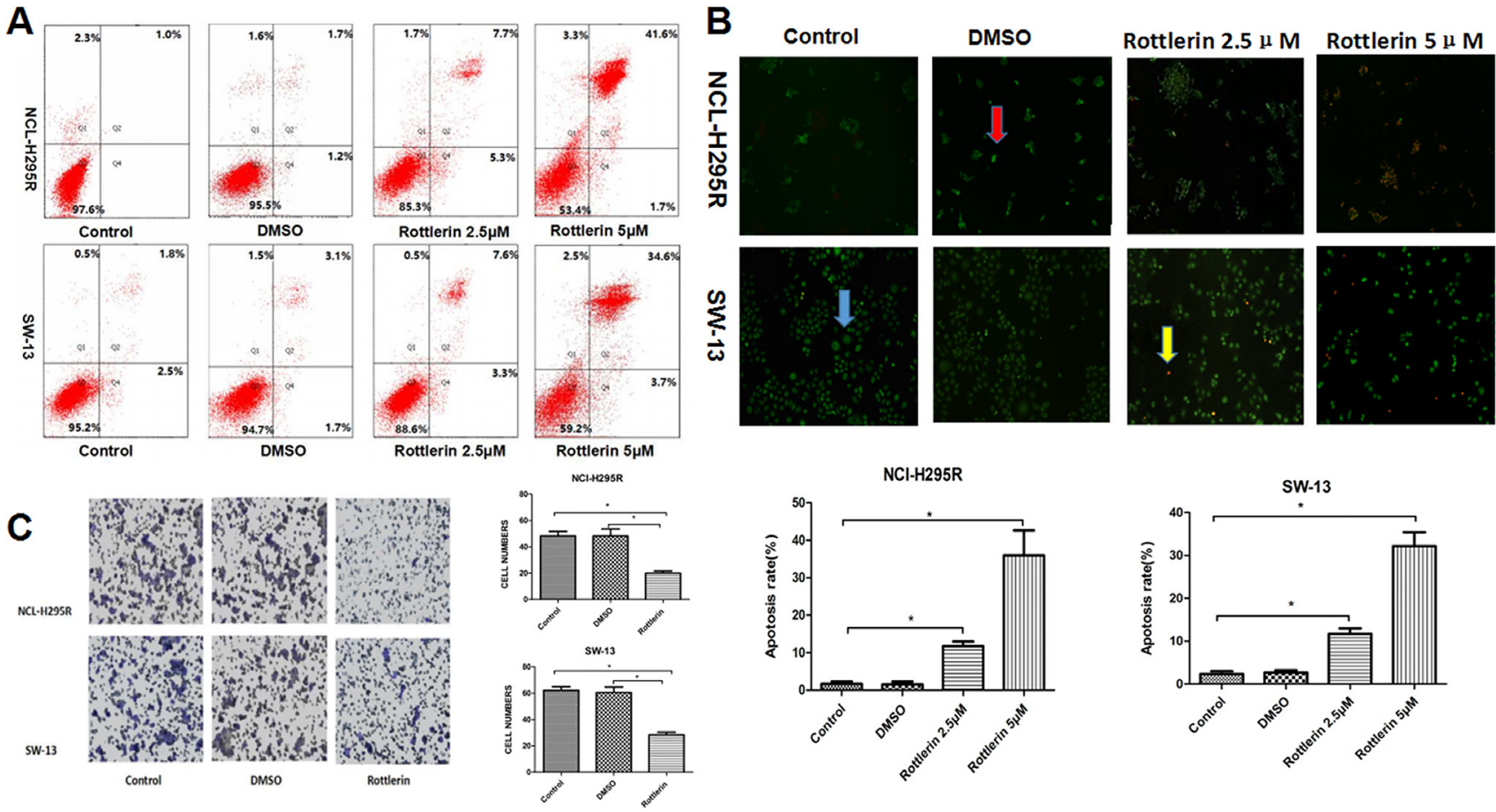

Figure 2: (A) Flow cytometric analysis of annexin-V/PI staining of NCI-H295R and SW-13 cells. Cells were treated with rottlerin at the indicated concentration $(2.5 \mu \mathrm{M}$ or $5 \mu \mathrm{M})$ for $48 \mathrm{~h}$. The dual parameter dot plots combining annexin-V-fluorescein isothiocyanate (FITC) and PI fluorescence show the viable cell population in the lower left quadrant (annexin-V2, PI2), apoptotic cells in the lower right quadrant (annexin-V+, PI2) and upper right quadrant (annexin $\mathrm{V}+, \mathrm{PI}+$ ), and necrotic cells in the upper left quadrant (annexin-V2, PI+). (B) Morphologic changes of ACC cells based on AO/EB staining. After treatment with rottlerin $(2.5 \mu \mathrm{M}$ or $5 \mu \mathrm{M})$ for $48 \mathrm{~h}$, apoptosis was observed using a fluorescence microscope.In order to indicate, the blue arrow point to a normal cell, the red arrow point to an early apoptotic cell, and the yellow arrow point to a late apoptotic cell. The rate of apoptosis in the rotterlin-treated group was higher compared with the control and DMSO groups $(* p<0.05)$. The apoptotic rate of cells in the higher concentration groups after treatment with $5 \mu \mathrm{M}$ rottlerin for $48 \mathrm{~h}$ was higher compared with the lower concentration groups $\left({ }^{*} p<0.05\right)$. (C) The transwell invasion and migration assay showed that rottlerin inhibited cell invasion and migration of ACC cells $(* p<0.05)$. 
family to activate the $\mathrm{Wnt} / \beta$-catenin signaling pathway [23]. LRP6 is expressed in human cancer cell lines and up-regulated in human malignant tissues [24], and LRP6 silencing weakens $W n t / \beta$-catenin signaling and inhibits cell proliferation and tumor growth in breast and prostate cancers [25]. LRP6 is readily expressed in ACC cells [26], but there has been limited research involving LRP6 in ACC. In our study, LRP6 and its phosphorylated form (p-LRP6) were down-regulated by rottlerin in ACC cells, both in vitro and in vivo.

Blocking the Wnt signaling pathway is not the only mechanism underlying rottlerin anti-tumor activity. Some studies have indicated that rottlerin decrease carcinogenesis by impacting the mammalian target of rapamycin complex 1 (mTORC1) signaling [27]. Furthermore, rottlerin inhibits the markers of angiogenesis (COX-2, VEGF, VEGFR, and IL-8), and metastasis (MMP-2 and MMP-9), thus blocking production of tumorigenic mediators in the tumor microenvironment [28]. Rottlerin also inhibits epithelial-mesenchymal transition by up-regulating E-cadherin [29, 30]. According to these studies, we know that the anti-neoplastic activity of rottlerin is a multiple-signal pathway. The anti-tumor activity of rotterlin against ACC warrants further study.

The recommended chemotherapy regimens for ACC are etoposide +doxorubicin+cisplatin+mitotane $(\mathrm{EDP} / \mathrm{M})$ or streptozotocin+mitotane $(\mathrm{Sz} / \mathrm{M})$. Whatever the chemotherapy regimen, mitotane is a key agent; however, the effective rate of treatment is only approximately $40 \%$. Moreover, mitotane has intense side effects, thus limiting its clinical use $[31,32]$. In this study, we attempted to identify a novel agent which suppresses ACC more efficiently and safer than traditional therapy. Based on our results, rottlerin is a novel and potential chemotherapeutic agent for ACC based on multiple signal pathway-related anti-neoplastic activity.

Further studies should involve clinical trials better defining the anti-neoplastic activity of combination rottlerin and traditional chemotherapeutics or cytotoxic drugs.

\section{MATERIALS AND METHODS}

\section{Cell lines and culture}

The ACC cell lines, NCI-H295R and SW-13, were purchased from the Cell Repository of the Chinese Academy of Science and originated from the American Type Culture Collection (ATCC; Manassas, VA, USA). The NCI-H295R cell line was cultured in DMEM (GIBCO, Grand Island, NY,USA), supplemented with $10 \%$ fetal bovine serum (MPBIO, Carlsbad, CA, USA) in a standard humidified incubator at $37^{\circ} \mathrm{C}$ in a $5 \% \mathrm{CO}_{2}$ atmosphere. The SW-13 cell line was cultured in L15 media (GENOM, Shanghai, China) supplemented with $10 \%$ fetal bovine serum in a standard humidified incubator at $37^{\circ} \mathrm{C}$ in an atmosphere without $\mathrm{CO}_{2}$.

\section{Drugs and antibodies}

R00ottlerin was purchased from Sigma Aldrich (St. Louis, MO, USA). Rottlerin was dissolved in dimethyl
A
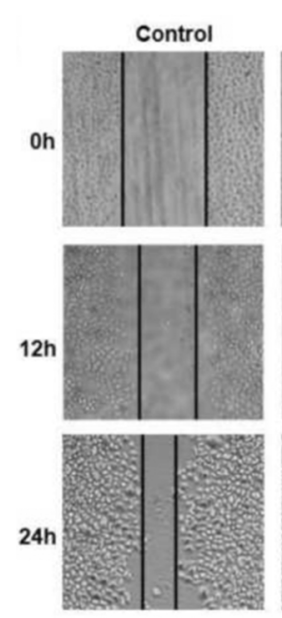
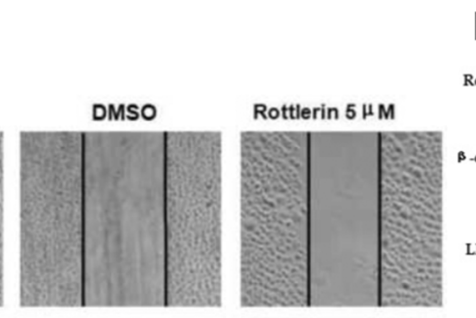

B

$\mathrm{NCl}-\mathrm{H} 295 \mathrm{R}$

SW-13
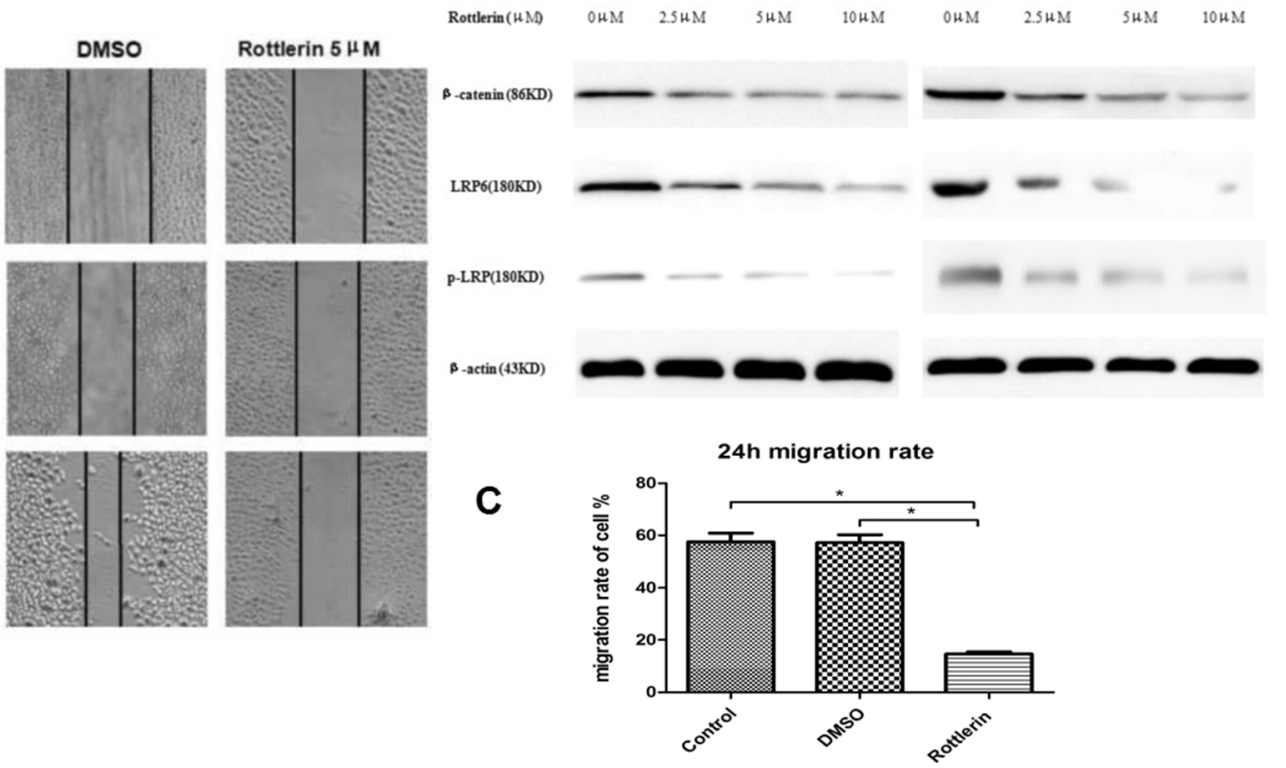

Figure 3: (A) The wound healing assay showed that rottlerin reduced the cell migration rate of SW-13 cells compared with the control and DMSO groups. (B) WB assays of $\beta$-catenin, LRP6, and p-LRP were performed in NCI-H295R and SW-13 cells. The results showed that rottlerin down-regulated the expression of $\beta$-catenin, LRP6, and p-LRP in a dose-dependent manner. (C) The $24 \mathrm{~h}$ migration of SW-13 decreased after rottlerin treatment compared with the control and DMSO-treated groups $\left({ }^{*} p<0.05\right)$. 
sulfoxide (DMSO; GIBCO) at $10 \mathrm{mM}$ and stored in dark at $4^{\circ} \mathrm{C}$. The final concentrations of rottlerin used for different experiments were prepared by diluting the stock solution with media solution. The antibodies used for Western blotting and immunohistochemistry staining were as follows: anti-LRP6 and anti-p-LRP6 antibodies were purchased from Affinity Bioscience (Cincinnati, $\mathrm{OH}$, USA); and anti- $\beta$-catenin antibody was purchased from ABCAM (San Francisco, CA, USA).

\section{Cell viability}

NCI-H295R and SW-13 cells were plated at a density of 2000 cells/well in flat bottom 96-well plates $(100 \mu \mathrm{l}$ media per well). After $24 \mathrm{~h}$, cells were treated with rottlerin at various concentrations $(0,0.5,1,2,4$, and $8 \mu \mathrm{M})$ in the dark. Cell viability was measured after 24, 48, 72, 96, and $120 \mathrm{~h}$ using the Cell Counting Kit 8 (Dojindo, Osaka, Japan) with a microplate reader at $450 \mathrm{~nm}$. All experimental concentrations were assessed in triplicate. The half maximal inhibitory concentration (IC50) was calculated with GraphPad Prism 5.

\section{Apoptosis analyses by flow cytometry}

NCI-H295R and SW-13 cells were cultured in 6-well plates and treated with rottlerin in the dark (concentration : $5 \mu \mathrm{M}$ and $2.5 \mu \mathrm{M}$ ). The control group was not treated with rottlerin and a DMSO treated-group was established as well. After incubation for $48 \mathrm{~h}$, cells were harvested, washed with PBS twice, resuspended in binding buffer, stained with an annexin-V/PI solution (Dojindo) at room temperature, then analyzed using a FACScan system (BD Biosciences, San Jose, CA, USA).

\section{Acridine orange/ethidium bromide (AO/EB) staining}

Morphologic assessment of apoptotic cells was performed using the AO/EB staining method. NCIH295R and SW-13 cells were cultured in 6-well plates $\left(5 \times 10^{4}\right.$ cells $\left./ \mathrm{ml}\right)$. After a $24-\mathrm{h}$ incubation, the cells were treated with rottlerin in the dark (concentration $=5 \mu \mathrm{M}$ and $2.5 \mu \mathrm{M}$ ) for $48 \mathrm{~h}$. After washing twice with PBS, the cells were stained with $1 \mathrm{ml}$ of AO/EB (Sigma Aldrich)
A

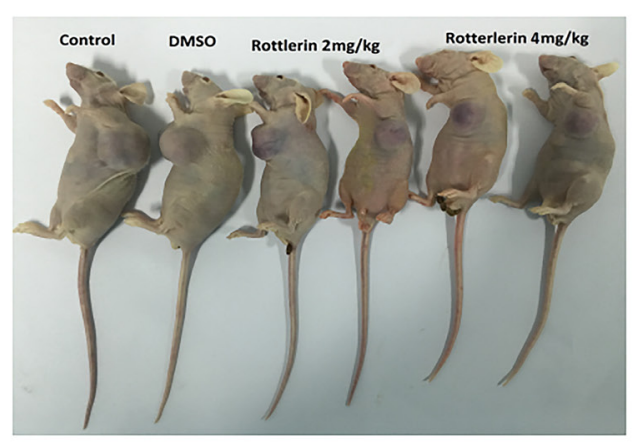

C

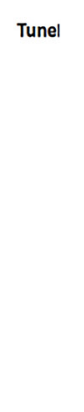

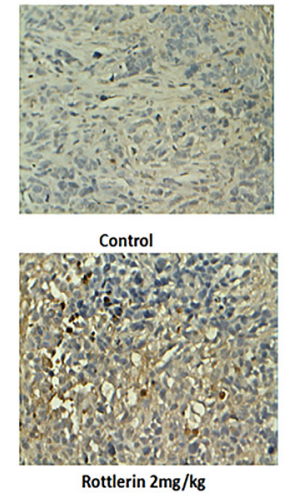
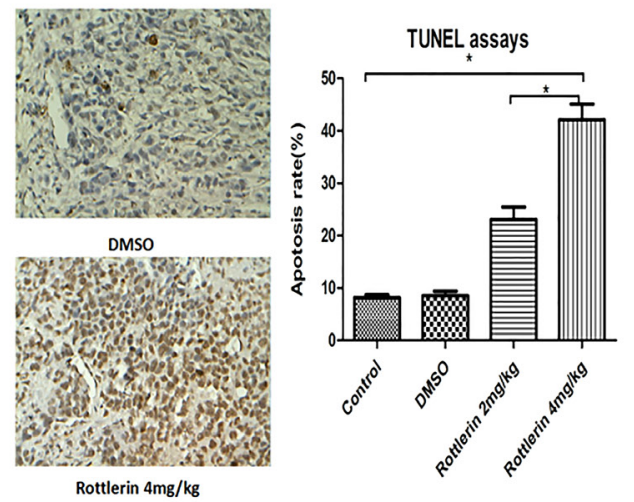

B
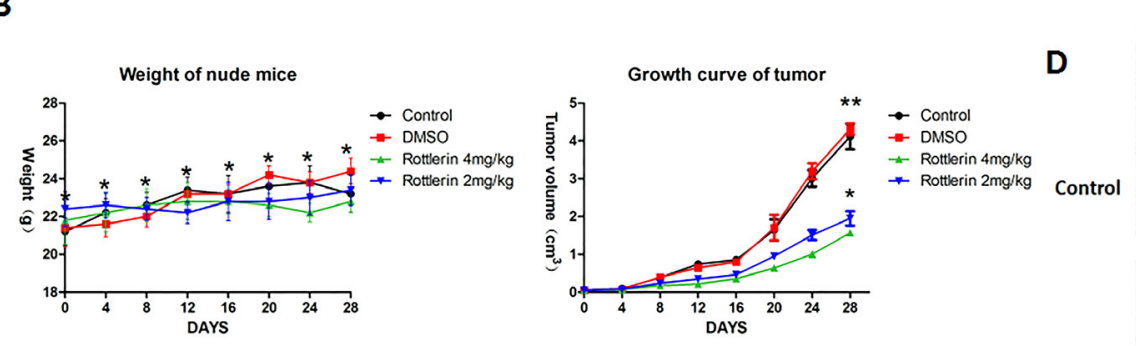

\section{H\&E Staining}
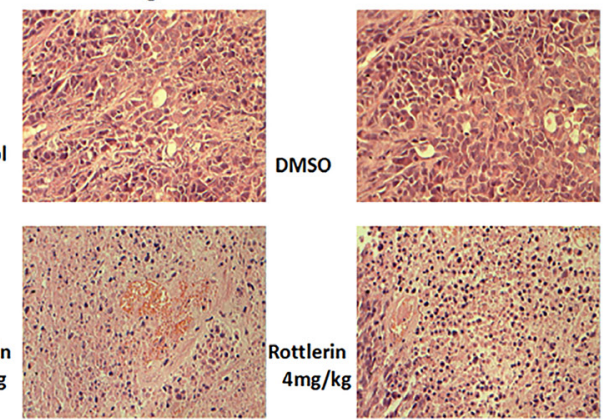

Figure 4: (A) Tumors in the rottlerin-treated groups were smaller than the control and DMSO-treated groups. (B) There was no significant difference in weight among the groups $(* p>0.05)$, and the rottlerin-treated groups showed delayed tumor growth compared to the control and DSMO-treated groups $\left({ }^{*} p<0.05\right)$; there was no significant difference in tumor volume between the control and DSMO-treated groups $(* * p>0.05)$. Tumors in the rottlerin $4 \mathrm{mg} / \mathrm{kg}$ group grow more slowly compared with the rottlerin $2 \mathrm{mg} / \mathrm{kg}$ group $\left({ }^{*} p<0.05\right)$. (C) Tunnel assays indicated that rottlerin induced apoptosis in vivo. The tumor sections were observed under a light microscope. The apoptotic cells appeared brown in color, when the normal cells appeared blue. The apoptotic rates of the groups showed that the rottlerin-treated groups had higher apoptotic rates than the control and DMSO-treated groups $(* p<0.05)$. The apoptotic rate in the rottlerin $4 \mathrm{mg} / \mathrm{kg}$ group was higher than the rottlerin $2 \mathrm{mg} / \mathrm{kg}$ group ( $* p<0.05$ ). (D) Hematoxylin and eosin (H\&E) staining of tumor tissue. 
for $3 \mathrm{~min}$ and imaged under an inverted fluorescence microscope.Five hundred cells were counted under a microscope $($ magnification $=200 \times)$. The apoptosis rate was calculated using the following formula: apoptosis rate $=($ early apoptotic cells + late apoptotic cells $) /$ the total number of cells. The nuclei of early apoptotic cells had a bright green fluorescence, the late apoptotic cell nuclei had a bright orange fluorescence, and the nuclei of normal cells had a ground glass-like dim green fluorescence.

\section{Cell cycle analyses by flow cytometry}

NCI-H295R and SW-13 cells were plated in 6-well plates. After a $24 \mathrm{~h}$ incubation, the cells were treated with rottlerin in the dark (concentration $=5 \mu \mathrm{M}$ and $2.5 \mu \mathrm{M}$ ) for $48 \mathrm{~h}$. The cells were collected, washed twice in cold PBS, mixed in $300 \mathrm{ml}$ of $1 \times$ binding buffer, and incubated at room temperature for $15 \mathrm{~min}$ with propidium iodide (PI), NP-40, and RNaseA (Beyotime, Shanghai, China). The cell cycle was analyzed by flow cytometry and the percentage of cells in the different phases was calculated using ModFit LT software (Verity Software House).

\section{Invasion and migration assay}

Cell invasion and migration were assessed using a Transwell chamber (GreinerBio, Frickenhausen, Germany) containing a polycarbonated filter with $81 \mathrm{M}$ pores coated with Matrigel (BD Biosciences, BD Biosciences,San Jose, CA, USA).The cells in the experimental group were pre-treated with the respective concentrations of rottlerin $(5 \mu \mathrm{M})$ for $24 \mathrm{~h}$. The cells $\left(1 \times 10^{5}\right)$ in $0.2 \mathrm{ml}$ of culture medium without fetal bovine serum were added to the upper chamber. The lower chamber was filled with $0.6 \mathrm{ml}$ of complete medium containing 30\% fetal bovine serum. After a $24 \mathrm{~h}$ incubation,cells remaining on the upper side of the transwell membrane were removed using a cotton swab.The membrane was washed with ice cold PBS twice.Cells that invaded the underside were fixed with $4 \%$ formaldehyde, stained with crystal violet, and counted in five randomly selected fields under a microscope (magnification of $200 \times$ ).

We also measured the migration rate using a wound healing assay.SW-13 cells were plated in 6-well plates $\left(1 \times 10^{6} \mathrm{cells} / \mathrm{ml}\right)$; after attachment the cells were scratched using a sterile pipette tip.The experimental group was treated with $5 \mu \mathrm{M}$ rottlerin. The cells were photographed at various time points $(0,12$, and $24 \mathrm{~h}$; magnification $=$ $100 \times)$. The migration rate at $24 \mathrm{~h}$ was calculated using the following formula:migration rate $=(1-$ the width of the cell wound at $24 \mathrm{~h} /$ the width of the cell wound at $0 \mathrm{~h}) \%$.

\section{Animal experiments}

Animal experiments were performed using 4-weekold male nude mice (athymic, BALB/C nu/nu), which were purchased from the Provincial Animal Center (Guangdong, China). The animal experiments were performed according to the Guide for the Care and Use of Laboratory Animals and approved by the Animal
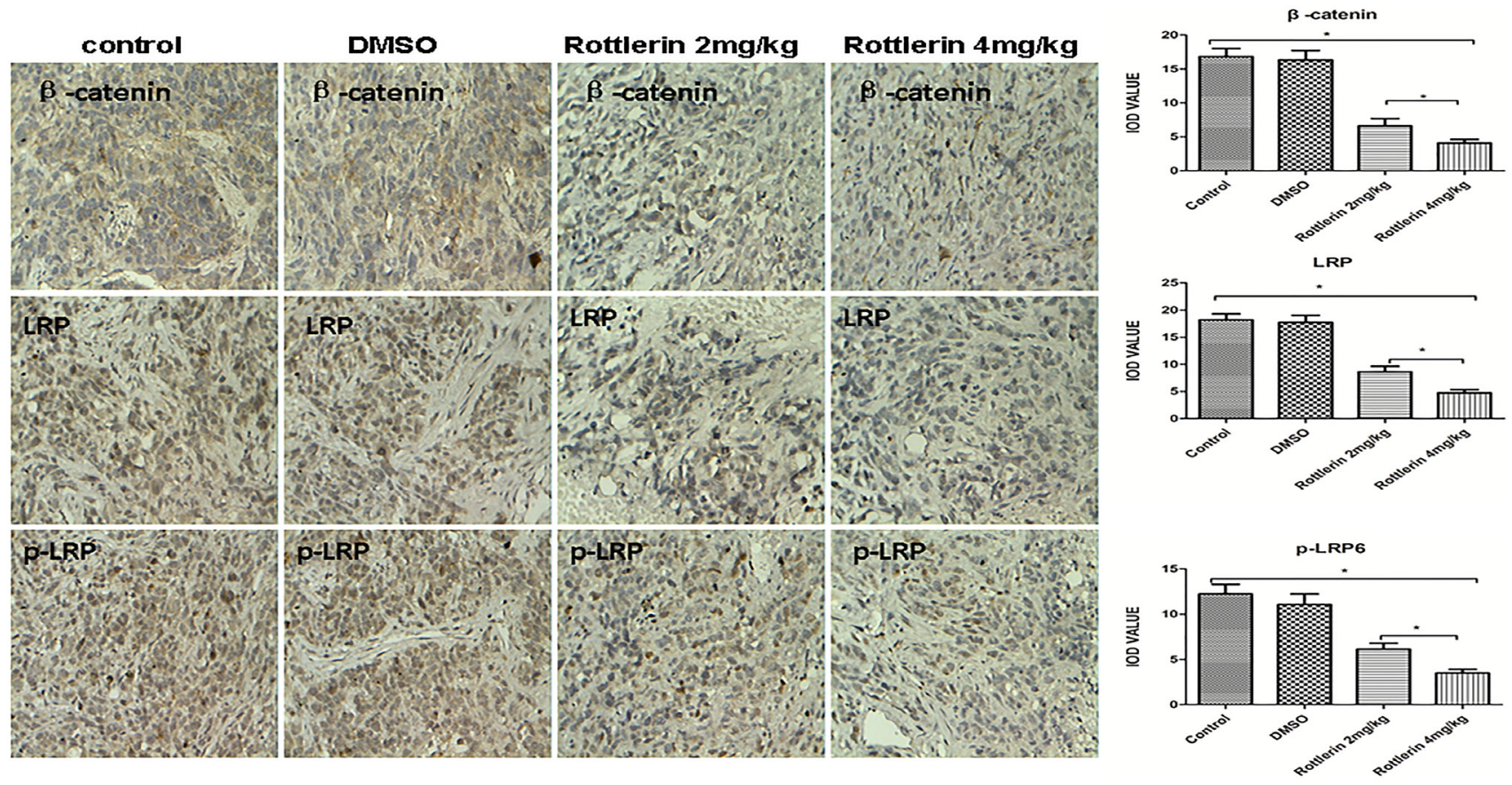

Figure 5: The expression of $\beta$-catenin, LRP6, and p-LRP by immunohistochemistry staining in xenograft tissues. The positive expressing proteins appeared brown in color.The results showed that rottlerin down-regulated the expression of $\beta$-catenin, LRP6, and p-LRP compared with the control and DMSO-treated groups $(* p<0.05)$ in vivo. The suppression was stronger in the higher dosetreated group (rottlerin $4 \mathrm{mg} / \mathrm{kg}$ ) than the lower dose-treated group (rottlerin $2 \mathrm{mg} / \mathrm{kg} ;{ }^{* *} p<0.05$ ). 
Investigation Committee of the General Hospital of Guangzhou Military Command. Mice were housed in a standard animal laboratory with free access to water and food. The mice were kept under constant environmental conditions with a $12 \mathrm{~h}$ light-dark cycle. SW-13 cells were $\left(3 \times 10^{6}\right.$ cells $)$ suspended in $200 \mu \mathrm{l}$ of serum-free culture medium and inoculated subcutaneously in the flank region of nude mice. Tumors were permitted to grow to approximately $4 \mathrm{~mm}$, and mice were randomized into 4 treatment groups (control, DMSO, rottlerin $4 \mathrm{mg} / \mathrm{kg}$, and rottlerin $2 \mathrm{mg} / \mathrm{kg}$ ) with 5 mice per group. All the mice were injected intraperitoneally daily for 4 weeks. Rottlerin was dissolved in DMSO, and diluted with normal saline (NS). The control group was injected with $0.5 \mathrm{ml}$ of NS and the DMSO group was injected with $0.45 \mathrm{ml}$ of NS mixed with $50 \mu \mathrm{l}$ of DSMO. The rottlerin groups were injected with rottlerin (4 $\mathrm{mg}$ or $2 \mathrm{mg}$ per kilogram). The mouse weights and tumor volumes were monitored every 4 days. Using Vernier calipers, the tumor volume was calculated according to the following formula: $\mathrm{A} \times \mathrm{B} \times \mathrm{B} / 2$, where $A$ is the length of the tumor and $B$ is the width. After 4 weeks, the mice were euthanized and the xenografts were removed from the animals. Tumor tissues were fixed in $10 \%$ formalin solution and paraffin-embedded. The sample sections were prepared for hematoxylin and eosin (HE) staining, immunohistochemistry staining, and terminal deoxynucleotidyl transferase dUTP nick end labeling (TUNEL) assays.

\section{Immunohistochemistry staining}

Tumor tissues sections from paraffin-embedded tumors were de-paraffinized and rehydrated using xylene and ethanol, and immersed in 3\% hydrogen peroxide solution for $10 \mathrm{~min}$ to block endogenous peroxidase. Sections were boiled for $30 \mathrm{~min}$ in $10 \mathrm{mM}$ citrate buffer solution $(\mathrm{pH}$ 6.0) for antigen retrieval. Slides were incubated for $45 \mathrm{~min}$ with $5 \%$ bovine serum albumin and incubated overnight at $4{ }^{\circ} \mathrm{C}$ with anti-LRP6, antip-LRP6, and anti- $\beta$-catenin antibodies. The specimens were incubated for $45 \mathrm{~min}$ at $37^{\circ} \mathrm{C}$ with the appropriate peroxidase-conjugated secondary antibody and visualized using the DAB Detection Kit (BOSTER, Shanghai, China) following the manufacturer's instructions. All sections with immunohistochemical staining were observed and the pictures of 6 randomly selected but homogeneous in staining and cell numbers fields $(400 \times)$ were photographed by an Olympus microscope (IX-70 OLYMPUS, Japan) under high power view. The integrated optical density (IOD) in each image was measured with the same setting for all the slides, and the results were analyzed with Image-ProPlus 6.0 software[33].

\section{TUNEL assays}

Tumor tissue sections from paraffin-embedded tumors were de-paraffinized and rehydrated using xylene and ethanol. The slides were rinsed twice with PBS and treated for $15 \mathrm{~min}$ at $37^{\circ} \mathrm{C}$ with proteinase $\mathrm{K}(15 \mathrm{mg} / \mathrm{ml}$ in $10 \mathrm{mM}$ Tris/ $\mathrm{HCl}$ [pH 7.4-8.0]). Endogenous peroxidases were blocked using 3\% hydrogen peroxide in methanol at room temperature for $10 \mathrm{~min}$. The tissue sections were then analyzed with an in situ Cell Death Detection KitPOD (Roche, Basel, Switzerland) in accordance with the manufacturer's instructions. The reaction was visualized using microscopy. Cell numbers of five randomly selected fields $(400 \times)$ were counted under a microscope and analyzed with Imaga-ProPlus 6.0 software.

\section{Western blotting}

NCI-H295R and SW-13 cells were treated with rottlerin in the dark (concentrations $=0,2.5,5$, and $10 \mu \mathrm{M}$ ) for $48 \mathrm{~h}$. The cells were washed twice with PBS solution, then lysed with RIPA Lysis Buffer (Beyotime, Shanghai, China) and a protease inhibitor (Thermo Scientific, Waltham, MA, USA). Protein concentrations were determined with a Pierce BCA Protein Assay Kit (Beyotime). Equivalent amounts of total protein $(60 \mu \mathrm{g})$ were boiled and electrophoretically separated on a $10 \%$ polyacrylamide gel at 80 volts. The proteins were transferred to a polyvinylidene difluoride membrane. The membranes were blocked for 60 min with a 5\% milk solution prepared in PBS. The membranes were incubated overnight at $4^{\circ} \mathrm{C}$ with 1:500 (anti-p-LRP6 and anti-LRP6) or 1:3000 (anti$\beta$-catenin) dilutions of the primary antibodies. The membranes were washed three times for $5 \mathrm{~min}$ each with Tween 20 (1:1000 dilution in PBS) and incubated for $45 \mathrm{~min}$ with the appropriate peroxidase-conjugated secondary antibody (1:5000 dilution). The membranes were washed with Tween 20-PBS three times for $10 \mathrm{~min}$ each and were developed using an Odyssey two-color infrared laser imaging system. The signal generated by $\beta$-actin was used as an internal control.

\section{Statistics}

Statistical analyses were performed using SPSS17.0 software and all the data from at least three experiments are presented as the mean \pm S.D. The statistical difference between the means was analyzed with a Student's $t$-test or one-way ANOVA. Compared with the control, a $p<0.05$ was considered to be statistically significant.

\section{ACKNOWLEDGMENTS}

We thank Dr. WANG Jie and Dr. XIA Bin for providing instructions for experiments, and Dr. WANG Wei for providing advise in experimental design.

\section{CONFLICTS OF INTEREST}

The authors declare that there are no conflicts of interest that could be perceived as prejudicing the impartiality of the research reported. 


\section{FUNDING}

This research did not receive any specific grant from any funding agency in the public, commercial, or not-forprofit sectors.

\section{Authors' contributions}

Conceived and designed the experiments: Weilie $\mathrm{Hu}$ and Yi Zhu. Performed the experiments: Yi Zhu, Minjie Wang,Xu Zhao, Lei Zhang.Analyzed the data: Yi Zhu, Minjie Wang,Yigao Wu and Bangqi Wang. Contributed reagents/materials/analysis tools: Yi Zhu, Minjie Wang, and Xu Zhao. Wrote the paper: Yi Zhu.

\section{REFERENCES}

1. Ayala-Ramirez M, Jasim S, Feng L, Ejaz S, Deniz F, Busaidy N, Waguespack SG, Naing A, Sircar K, Wood CG, Pagliaro L, Jimenez C, Vassilopoulou-Sellin R, et al. Adrenocortical carcinoma:clinical outcomes and prognosis of 330 patients at a tertiary care center. Eur J Endocrinol. 2013; 169:891-899.

2. Bilimoria KY, Shen WT, Elaraj D, Bentrem DJ, Winchester DJ, Kebebew E, Sturgeon C. Adrenocortical carcinoma in the United States:Treatment utilization and prognostic factors. Cancer. 2008; 113:3130-3136.

3. Fassnacht M, Kroiss M, Allolio B. Update in Adrenocortical Carcinoma. J Clin Endocrinol Metab. 2013; 98:4551-4564.

4. Costa R, Carneiro BA, Tavora F, Pai SG, Kaplan JB, Chae YK, Chandra S, Kopp PA, Giles FJ. The challenge of developmental therapeutics for adrenocortical carcinoma. Oncotarget. 2016; 7:46734-36749. doi: 10.18632/ oncotarget.8774.

5. Hong KK, Ball GE, Black DS, Kumar N. The Mosaic of Rottlerin. J Org Chem. 2015; 80:10668-10674.

6. Daveri E, Valacchi G, Romagnoli R, Maellaro E, Maioli E. Antiproliferative Effect of Rottlerin on Sk-Mel-28 Melanoma Cells. Evid Based Complement Alternat Med. 2015; 2015:545-554.

7. Lu W, Lin C, Li Y. Rottlerin induces Wnt co-receptor LRP6 degradation and suppresses both Wnt/ $\beta$-catenin and mTORC1 signaling in prostate and breast cancer cells. Cell Signal. 2014; 26:1303-1309.

8. Wang C, Sun Y, Wu H, Zhao D, Chen J. Distinguishing adrenal cortical carcinomas and adenomas:a study of clinicopathological features and biomarkers. Histopathology. 2014; 64:567-576.

9. Bonnet S, Gaujoux S, Launay P, Baudry C, Chokri I, Ragazzon B, Libé R, René-Corail F, Audebourg A, VacherLavenu MC, Groussin L, Bertagna X, Dousset B, et al. Wnt/ $\beta$-catenin pathway activation in adrenocortical adenomas is frequently due to somatic CTNNB1-activating mutations, which are associated with large and nonsecreting tumors:a study in cortisol-secreting and -nonsecreting tumors. J Clin Endocrinol Metab. 2011; 96:419-426.

10. Heaton JH, Wood MA, Kim AC, Lima LO, Barlaskar FM, Almeida MQ, Fragoso MC, Kuick R, Lerario AM, Simon DP, Soares IC, Starnes E, Thomas DG, et al. Progression to adrenocortical tumorigenesis in mice and humans through insulin-like growth factor 2 and $\beta$-catenin. Am J Pathol. 2012; 181:1017-1033.

11. Ross JS, Wang K, Rand JV, Gay L, Presta MJ, Sheehan CE, Ali SM, Elvin JA, Labrecque E, Hiemstra C, Buell J, Otto GA, Yelensky R, et al. Next-generation sequencing of adrenocortical carcinoma reveals new routes to targeted therapies. J Clin Pathol. 2014; 67:968-973.

12. Glover AR, hao JT, Ip JC, Lee JC, Robinson BG, Gill AJ, Soon PS, Sidhu SB. Long noncoding RNA profiles of adrenocortical cancer can be used to predict recurrence. Endocrine-Related Cancer. 2015; 22:99-110.

13. Else T, Williams AR, Sabolch A, Jolly S, Miller BS, Hammer GD. Adjuvant therapies,patient and tumor characteristics associated with survival of adult patients with adrenocortical carcinoma. J Clin Endocrinol Metab. 2014; 99:455-461.

14. Choi YM, Kwon H, Jeon MJ, Sung TY, Hong SJ, Kim TY, Kim WB, Shong YK, Lee JL, Song DE, Kim WG. Clinicopathological Features Associated With the Prognosis of Patients With Adrenal Cortical Carcinoma:Usefulness of the Ki-67 Index. Medicine. 2016; 95:e3736.

15. Ashour AA, Abdel-Aziz AA, Mansour AM, Alpay SN, Huo L, Ozpolat B. Targeting elongation factor-2 kinase (eEF-2K) induces apoptosis in human pancreatic cancer cells. Apoptosis. 2014; 19:241-258.

16. Ohno I, Eibl G, Odinokova I, Edderkaoui M, Damoiseaux RD, Yazbec M, Abrol R, Goddard WA 3rd, Yokosuka O, Pandol SJ, Gukovskaya AS. Rottlerin stimulates apoptosis in pancreatic cancer cells through interactions with proteins of the Bcl-2 family. Am J Physiol Gastrointest Liver Physiol. 2010; 298:63-73.

17. Parviainen H1, Schrade A, Kiiveri S, PrunskaiteHyyryläinen R, Haglund C, Vainio S, Wilson DB, Arola J, Heikinheimo M. Expression of Wnt and TGFßpathway components and key adrenal transcription factors in adrenocortical tumors -association to carcinoma aggressiveness. Pathol Res Pract. 2013; 209:503-509.

18. Cadigan KM, Liu YI. Wnt signaling:complexity at the surface. J Cell Sci. 2006; 119:395-402.

19. Tanabe S, Aoyagi K, Yokozaki H, Sasaki H. Regulation of CTNNB1 signaling in gastric cancer and stem cells. World J Gastrointest Oncol. 2016; 158:592-598.

20. Weiss V, Dueber J, Wright JP, Cates J, Revetta F, Parikh AA, Merchant NB, Shi C. Immunohistochemical analysis of the $\mathrm{Wnt} / \beta$-catenin signaling pathway in pancreatic neuroendocrine neoplasms. World J Gastrointest Oncol.2016; 158:615-622. 
21. Lefvre L, Omeiri H, Drougat L, Hantel C, Giraud M, Val P, Rodriguez S, Perlemoine K, Blugeon C, Beuschlein F, de Reyniès A, Rizk-Rabin M, Bertherat $\mathrm{J}$, et al. Combined transcriptome studies identify AFF3 as a mediator of the oncogenic effects of $\beta$-catenin. Oncogenesis. 2015; 4:1-10.

22. Salomon A, Keramidas M, Maisin C, Thomas M. Loss of $\beta$-catenin in adrenocortical cancer cells causes growth inhibition and reversal of epithelial-to-mesenchymal transition. Oncotarget. 2015; 6:11421-11433. doi: 10.18632/oncotarget.3222.

23. Ring L, Neth P, Weber C, Steffens S, Faussner A. $\beta$-catenindependent pathway activation by both promiscuous "canonical" WNT3a-,and specific "noncanonical" WNT4and WNT5a-FZD receptor combinations with strong differences in LRP5 and LRP6 dependency. Cell Signal. 2014; 26:260-267.

24. Freeman J, Smith D, Latinkic B, Ewan K, Samuel L, Zollo M, Marino N, Tyas L, Jones N, Dale TC. A functional connectome:regulation of Wnt/TCF-dependent transcription by pairs of pathway activators. Mol Cancer.2015; 14:206-213.

25. Lu W, Lin C, Roberts MJ, Waud WR, Piazza GA, Li Y. Niclosamide Suppresses Cancer Cell Growth By Inducing Wnt Co-Receptor LRP6 Degradation and Inhibiting theWnt/ $\beta$-catenin Pathway. PLoS One. 2011; 6:290-297

26. El Wakil A, Lalli E. The Wnt/beta-catenin pathway in adrenocortical development and cancer. Mol Cell Endocrinol. 2011; 30:32-37.

27. Daveri E, Maellaro E, Valacchi G, Ietta F, Muscettola M, Maioli E. Inhibitions of mTORC1 and 4EBP-1 are key events orchestrated by Rottlerin in SK-Mel-28 cell killing. Cancer Lett. 2016; 380:106-113.
28. Huang M, Tang SN, Upadhyay G, Marsh JL, Jackman CP, Srivastava RK, Shankar S. Rottlerin suppresses growth of human pancreatic tumors in nude mice, and pancreatic cancer cells isolated from $\mathrm{Kras}(\mathrm{G} 12 \mathrm{D})$ mice. Cancer Lett. 2014; 353:32-40.

29. Torricelli C, Daveri E, Salvadori S, Valacchi G, Ietta F, Muscettola M, Carlucci F, Maioli E. Phosphorylationindependent mTORC1 inhibition by the autophagy inducer Rottlerin. Cancer Lett. 2015; 60:17-27.

30. Woo SM, Lee WK, Min KJ, Kim DE, Park SH, Nam SI, Kwon TK. 2016 Rottlerin induces cyclooxygenase-2 upregulation through an ATF4 and reactive oxygen speciesindependent pathway in HEI-OC1 cells. Mol Med Rep. 2016; 14:845-850.

31. Berruti A, Terzolo M, Sperone P, Pia A, Della Casa S, Gross DJ, Carnaghi C, Casali P, Porpiglia F, Mantero F, Reimondo G, Angeli A, Dogliotti L. Etoposide, doxorubicin andcisplatin plus mitotane in the treatment of advanced adrenocortical carcinoma:a large prospective phase II trial. Endocr Relat Cancer. 2005; 12:657-66.

32. Fassnacht M, Terzolo M, Allolio B, Baudin E, Haak H, Berruti A, Welin S, Schade-Brittinger C, Lacroix A, Jarzab B, Sorbye H, Torpy DJ, Stepan V, et al. Combination chemotherapy in advanced adrenocortical carcinoma. New England Journal of Medicine. 2012; 366:2189-2197.

33. Jing YY Liu WT, Guo SW, Ye F, Fan QM, Yu GF, Yu DD, Gao L, Sun K, Han ZP, Li R, Yang Y, Zhao QD, et al. Hepatitis B virus (HBV) receptors: Deficiency in tumor results in scant $\mathrm{HBV}$ infection and overexpression in peritumor leads to higher recurrence risk. Oncotarget. 2015; 6:42952-62. doi: 10.18632/oncotarget.5518. 